Zühtü Hakan Akpolat, Mustafa Can Bingöl, Mustafa Ay, Gonca Özmen Koca, Cafer Bal, Deniz Korkmaz

Fırat University, Elazığ-Turkey

z.h.akpolat@gmail.com, mustafacanbingol@gmail.com, mustafaay23@hotmail.com, gonca.ozmen@gmail.com, caferbal@gmail.com, denizkorkmaz17@gmail.com,

\title{
http://dx.doi.org/10.12739/NWSA.2017.12.1.1A0370
}

\section{DYNAMIC MODEL AND SIMULATION OF ONE ACTIVE JOINT ROBOTIC FISH}

\section{ABSTRACT}

This study considers the dynamic model of one active joint robotic fish by using Lagrange method and simulation of the robotic fish model in MATLAB/SimMechanics environment. Compared results of these two different models are given in the study. The mathematical model of the system is derived from Lagrange energy equations of the robotic fish inspired from a real carangiform fish. The Computer Aided Design (CAD) model of the robotic fish is designed by using SolidWorks and it is transferred to the SimMechanics environment. The hydrodynamic effects, which are linear and nonlinear drag force, are also adapted and head motion, one active joint, and one passive joint angles found by using MATLAB Simulink environment. Obtained results for joint angles from both dynamic and SimMechanics models are compared and proved with animation video of the robotic fish.

Keywords: Robotic Fish, Dynamic Model, SimMechanics Model, Mathematical Model, Biomimetic Design

\section{BİR AKTİF EKLEMLI ROBOT BALIĞIN DİNAMİK MODELİ VE BENZETİMI}

\section{Öz}

Bu çalışma Lagrange yöntemleri ile elde edilen aktif bir eklemli robot balığın dinamik modelini ve bu robot balığın MATLAB/SimMechanics ortamında benzetimini içermektedir. Bu iki farklı modelin karşılaştırmalı sonuçları bu çalışmada verilmiştir. Gerçek carangiform türünden bir balıktan esinlenilen sistemin matematik modeli Langrange enerji fonksiyonları yardımı ile elde edilmiştir. Bilgisayar Destekli Tasarım (CAD) modeli Solidworks kullanılarak tasarlanmış ve SimMechanics ortamına aktarılmıştır. Ayrıca lineer ve lineer olamayan hidrodinamik etkiler MATLAB Simulink ortamında bulunan baş hareketine, aktif ekleme ve pasif ekleme uygulanmıştır. Eklem açıları için hem dinamik hem de SimMechanics modellerinden elde edilen sonuçlar karşılaştırılmış ve robot balık animasyonu ile kanıtlanmıştır.

Anahtar Kelimeler: Robot Balık, Dinamik Model, SimMechanics Model, Matematiksel Model, Biomimetic Tasarım

How to Cite:

Akpolat, Z.H., Bingöl, M.C., Ay, M., Özmen Koca, G., Bal, C., and Korkmaz, D., (2017). Dynamic Model and Simulation of One Active Joint Robotic Fish, Engineering Sciences (NWSAENS), 12 (1):29-39, DOI: 10.12739/NWSA.2017.12.1.1A0370. 


\section{INTRODUCTION}

Recently, Robotic fish have been becoming more and more popular topic for researchers. It is known that fish swim by bending their bodies, fins and tails. Fish can achieve more propulsion efficiency and more maneuverability than classic propeller systems. By inspiring from these amazing features autonomous underwater vehicles named robotic fish have been developed since 1990s [from 1 to 7]. To design biological structure of a real fish, an appropriate dynamic model should be derived. The whole dynamic model includes both kinematic and hydrodynamic models. First researches about hydrodynamic of the robotic fish were investigated by Triantafyllou and Hirata [6 and 7]. Zhou et al. derived the mathematic model of robotic fish by using Lagrange method [8]. Suebsaiprom and Lin produced two joint robotic fish based on carangiform motion and three dimensional trajectory tracking was implemented [9]. Wang et al. derived dynamic model of one joint robotic fish and compared with experimental studies [10].

Importance of fish in robotic applications and their swimming abilities are mentioned at previous paragraph. Hence, most of studies about robotic fish have concentrated to obtain smooth fish like motion. In 2000s, various multi joint robotic fish were developed and verified with their dynamic models [11]. For instance, Kumar et al. researched a robotic fish inspired from a carangiform fish. The robotic fish can swim long distance and reach extremely speed [12]. Zhou et al. studied European eel's swimming locomotion in 2008. They obtained the dynamic model of the fish by using Lagrange Methods. After the model was derived, backward swimming mode of a real fish was mimicked by simulated with the dynamic model [13].

MATLAB/SimMechanics environment can be used to achieve easier dynamic model of the robotic systems than complex mathematical equations. SimMechanics was launched as a toolbox in 2008 by MathWorks Company and many mechanical systems have been modelled by using this toolbox. In the literature, many studies have been given. Dung et al. modelled a robot manipulator by using SimMechanics Toolbox [from 14 to 18]. CAD model of a loader was designed by Liu, which is often preferred for engineering projects such as dam and viaduct construction. This model was also imported to SimMechanics [15]. At the same time, mathematical model of a 3-DOF parallel robot mechanism was obtained by Newton-Euler and compared with SimMechanics model. These studies show that the mathematical model of a robotic mechanism can be designed and verified in SimMechanics environment [16-18].

\section{RESEARCH SIGNIFICATION}

In this study, dynamic model of the one active joint robotic fish inspired from a real carangiform fish is derived by using Lagrange method. This dynamic model including both kinematic and hydrodynamic effects is realized in MATLAB. Also, a Computer Aided Design (CAD) model of the robotic fish is drawn in SolidWorks and transferred to MATLAB/SimMechanics environment. Finally, comparison results of both dynamics and SimMechanics models are given and proved with animations. The rest of this paper is arranged as follows: In section II, dynamic model of the robotic fish is derived. SimMechanics model is given in Section III. Compared results are illustrated in section IV. Finally, conclusions are given in Section $\mathrm{V}$.

\section{PROBLEM DESCRIPTION}

\subsection{Motion Model}

Dynamic model of the robotic fish must be derived in order to control and analysis to this robotic system. Because of this 
obligation, biological system, which is real fish, is considered as a mechanic system similar to a robot arm. This approach is shown in Figure 1 .

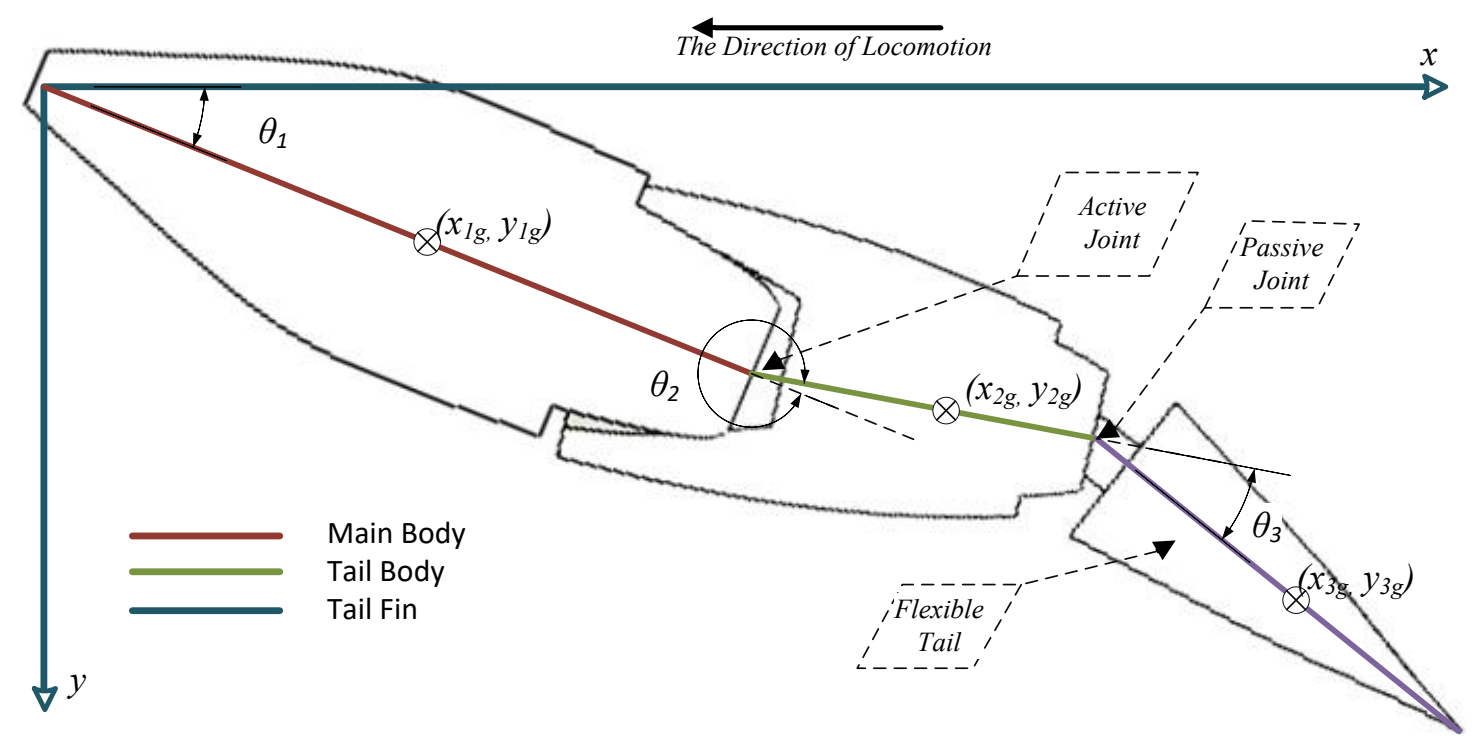

Figure 1. Robotic fish considering as a robot arm

Lagrange method is used to create matematical model of the robotic fish. Thus, center of mass coordinate of every link has to be found. Owing to this reason, Denavit - Hartenberg method is used with Equation (1) which is an translational matrix.

$$
{ }^{i-1} \operatorname{Tr}_{i}=\left[\begin{array}{cccc}
\cos \left(\theta_{i}\right) & -\sin \left(\theta_{i}\right) \cos \left(a_{i, i+1}\right) & \sin \left(\theta_{i}\right) \sin \left(a_{i, i+1}\right) & A_{i, i+1} \cos \left(\theta_{i}\right) \\
\sin \left(\theta_{i}\right) & \cos \left(\theta_{i}\right) \cos \left(a_{i, i+1}\right) & -\cos \left(\theta_{i}\right) \sin \left(a_{i, i+1}\right) & A_{i, i+1} \sin \left(\theta_{i}\right) \\
0 & \sin \left(a_{i, i+1}\right) & \cos \left(a_{i, i+1}\right) & d_{i} \\
0 & 0 & 0 & 1
\end{array}\right]
$$

Where, $i$ is link number, $d$ and $\theta$ are displacement and rotation at $z$ axis, respectively. A and $\alpha$ are also displacement and rotation at $x$ axis, respectively. Also Tr typifies transformation of axes. After mass center position of every link, are located right column in the matrix, is found, Lagrange equation $(L)$ is applied to the robotic system. Equation (2) shows energy function;

$$
L=\frac{1}{2}\left(m_{1} \dot{x}_{1_{g}}{ }^{2}+m_{2} \dot{x}_{2_{g}}{ }^{2}+m_{3} \dot{x}_{3_{g}}{ }^{2}+m_{1} \dot{y}_{1_{g}}{ }^{2}+m_{2} \dot{y}_{2_{g}}{ }^{2}+m_{3} \dot{y}_{3_{g}}{ }^{2}+J_{1} \dot{\theta}_{1}^{2}+J_{2} \dot{\theta}_{2}^{2}+J_{3} \dot{\theta}_{3}^{2}\right)-V
$$

Where, $m$ is mass of the link and $J$ is inertia of the link. $\dot{x}, \dot{y}$ and $\dot{\theta}$ symbolize velocity of $x$ axis, velocity of $y$ axis, and angular velocity, respectively. In Equation (2) the potential energy $V$ equals to zero on account of two dimensional motions for the application. In order to obtain Lagrange equation for the system, derivation of the $L$ has to be found as below:

$$
\frac{d}{d t}\left(\frac{\partial L}{\partial \dot{q}_{k}}\right)-\frac{\partial L}{\partial q_{k}}-\sum_{i=1}^{c} \lambda_{i}\left(\frac{\partial f_{i}}{\partial \dot{q}_{i}}\right)=0
$$

Here, $q$ is each parameter of the system, $k$ is current index. $\lambda, f$ and $c$ symbolize Lagrange multiplier, system constraint and number of 
system restriction. Thus, the kinematic model of the robotic fish can be obtained.

\subsection{Hydrodynamic Force Model}

Hydrodynamic force model has vital importance, since this force directly affects the system. There are five hydrodynamic forces on tail fin shown in Figure 2 .

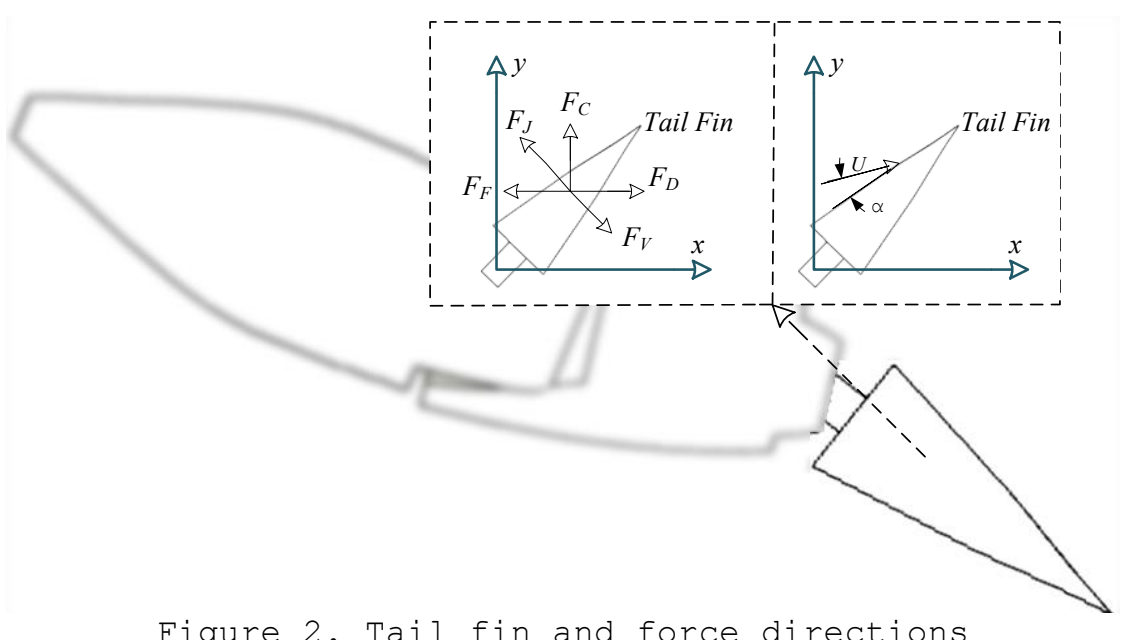

Figure 2. Tail fin and force directions

$\mathrm{Fj}$ and $\mathrm{Fv}$ are acceleration and lift force, respectively. These forces are given in Equation (4) and (5):

$$
F_{V}=\pi \rho L C^{2} \dot{U} \sin (a)+\pi \rho L C^{2} U \dot{a} \cos (a)
$$

$$
F_{J}=\pi \rho L C U^{2} \sin (2 a)
$$

Where, $\rho$ is density of water, $L$ is length of the $f i n, C$ is chord of the fin, $U$ is relative velocity at the center of the fin according to water and $\alpha$ is attack angel of the fin. Forces of the trust ( $\left.F_{F}\right)$ and yaw angle (FC) included $F_{J}$ and $F_{V}$ are given in Equation (6) and (7).

$$
F_{F}=\left(F_{J}\left(\sin \left(\theta_{1}\right)+\sin \left(\theta_{2}\right)+\sin \left(\theta_{3}\right)\right)-\left(F_{V}\left(\sin \left(\theta_{1}\right)+\sin \left(\theta_{2}\right)+\sin \left(\theta_{3}\right)\right)\right.\right.
$$

$F_{C}=\left(F_{V}\left(\cos \left(\theta_{1}\right)+\cos \left(\theta_{2}\right)+\cos \left(\theta_{3}\right)\right)-\left(F_{J}\left(\cos \left(\theta_{1}\right)+\cos \left(\theta_{2}\right)+\cos \left(\theta_{3}\right)\right)\right.\right.$

$\mathrm{F}_{\mathrm{F}}$ provides motion on $\mathrm{x}$ axis. $\mathrm{F}_{\mathrm{C}}$ provides motion on $\mathrm{y}$ axis. Equation (8) shows drag force;

$$
F_{D}=\frac{1}{2} C_{D} \dot{x}_{b}^{2} S_{x}+\frac{1}{2} C_{D} \dot{y}_{b}^{2} S_{y}
$$

where, $\dot{x}_{b}$ and $\dot{y}_{b}$ are velocity of the body at $\mathrm{x}$ and $\mathrm{y}$ axes, $S_{x}$ and $S_{y}$ are area of the wet surface at $x$ and $y$ axes and $C_{D}$ is shape coefficient, which are calculated by hydrodynamic analysis method. Five main forces mentioned in this part are added to the system input indicated with $\tau$ in motion model.

\section{SIMMECHANICS MODELLING OF THE ROBOTIC FISH}

The parts of the robotic fish are drawn by using solidWorks. The CAD model is assembled in this environment as shown in Figure 3. 


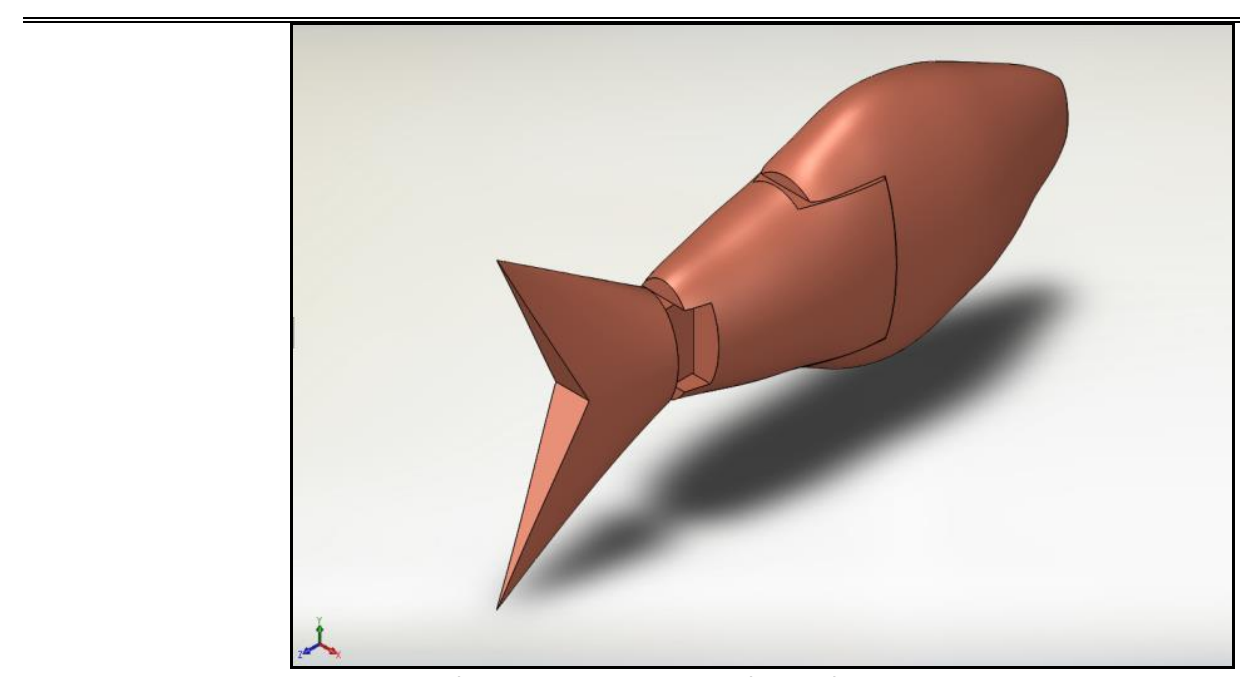

Figure 3. Robotic fish CAD model

After the robotic fish CAD model is designed, this model is transferred to SimMechanics environment as first generation without hydrodynamic effects. The first generation incomplete robotic fish model is illustrated in Figure 4. This model is incomplete, because hydrodynamic forces and motor effects are not applied to the SimMechanics model. Afterwards, these effects are added and whole model shown in Figure 5 is obtained. In this way, the complete model with hydrodynamic effects is also formed.

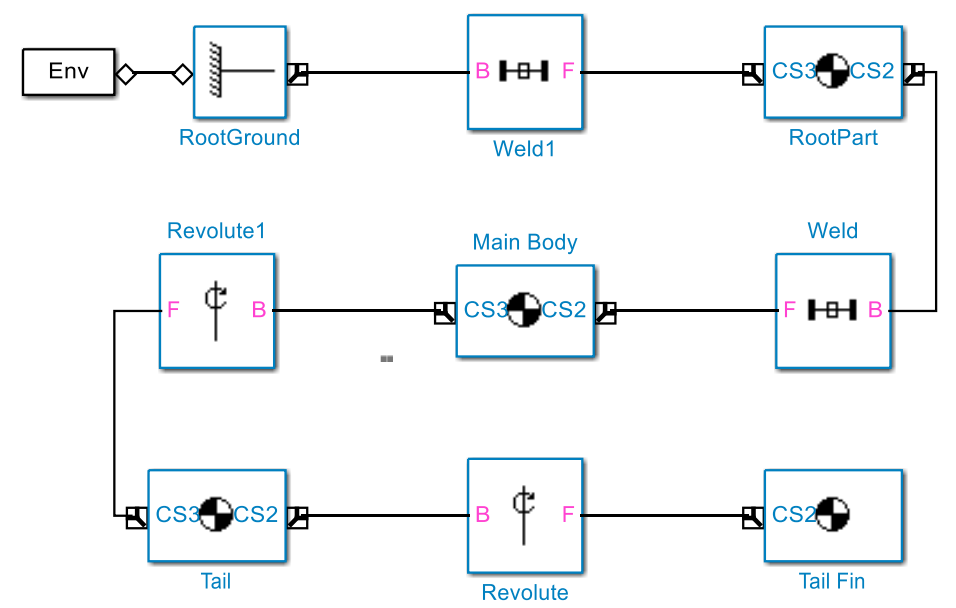

Figure 4. Incomplete Simmechanics model

Multi body simulation for 3D mechanical systems can be designed by SimMechanics environment. Nonlinear engineering models such as robotic and vehicle designs can also be created in this environment. Blocks representing bodies, joints, constraints, and force elements are used in this simulation model. Figure 6 shows the animation of the mechanical model of the robotic fish. 


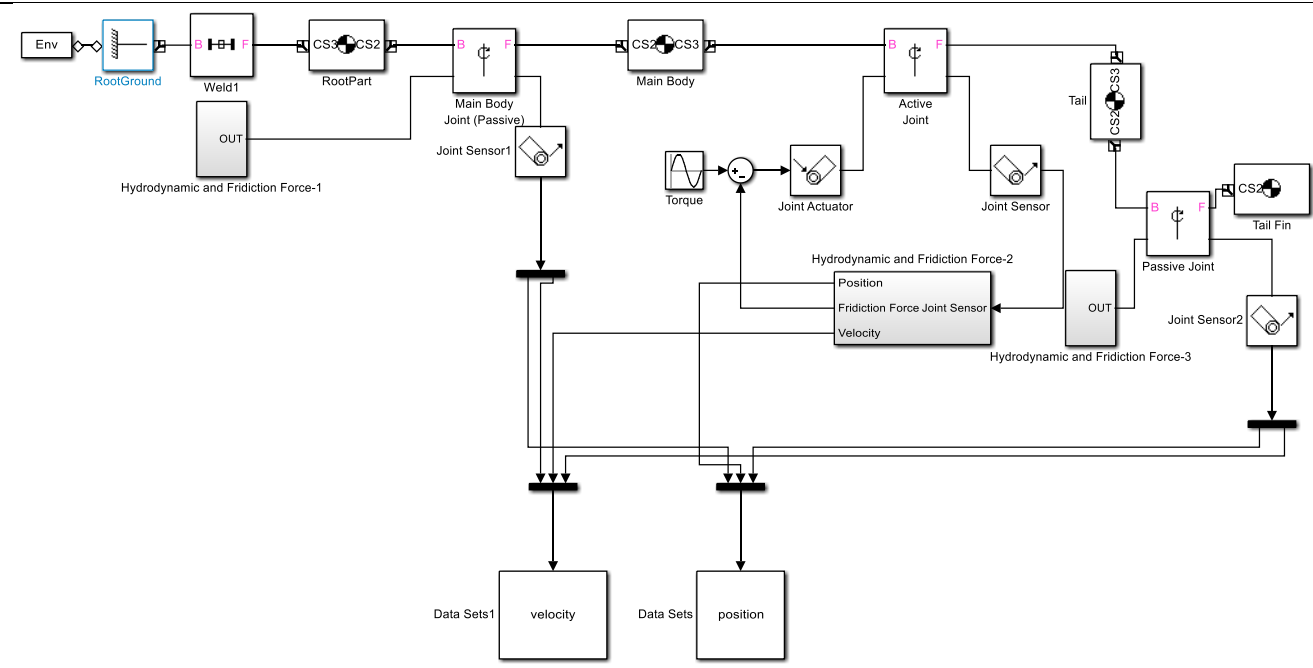

Figure 5. Complete robotic fish SimMechanics Model

CAD model of the robotic fish consisted from mass, joints, inertia and system constants are transferred to simMechanics to create 3D animation view of the mechanical model.

\section{RESULTS}

In this study, two individual models, which are given parameter Table 1: dynamic in MATLAB and 3D animation in MATLAB/SimMechanics are created to compare with each other. Simulation results are shown in from Fig. 6 to 11. Blue and red lines indicate results of the dynamic model and SimMechanics model, respectively. From Fig. 6 to 8 present angular velocity of main body, tail body and tail fin of the robotic fish. Since the robotic fish swim by using oscillation of fin, more precise results are obtained with dynamic model from main body to tail. However, SimMechanics model of robotic systems can be preferred instead of obtaining dynamic model as it is easy to create for the analysis. Considering all results, the error values between two models are acceptable to design a controller.

Table 1. Simulation parameters

\begin{tabular}{|c|c|c|c|}
\hline \multicolumn{5}{|c|}{ Values of Simulation } & Parameters \\
\hline Symbol & Definition & Value & Unit \\
\hline $\mathrm{m} 1$ & Mass of Main Body & 0.28826 & $\mathrm{~kg}$ \\
\hline $\mathrm{m} 2$ & Mass of Tail Body & 0.19552 & $\mathrm{~kg}$ \\
\hline $\mathrm{m} 3$ & Mass of Tail Fin & 0.15000 & $\mathrm{~kg}$ \\
\hline $\mathrm{J} 1$ & Inertia of Main Body & 0.0011 & $\mathrm{kgm}^{2}$ \\
\hline $\mathrm{J} 2$ & Inertia of Tail Body & $4.7 \mathrm{e}-04$ & $\mathrm{kgm}^{2}$ \\
\hline $\mathrm{J} 3$ & Inertia of Tail Fin & $1.2 \mathrm{e}-04$ & $\mathrm{kgm}^{2}$ \\
\hline $\mathrm{P}$ & Density of Fluid & 998.2071 & $\mathrm{~kg} / \mathrm{m}^{3}$ \\
\hline $\mathrm{L}$ & Length of Tail Fin & 0.075 & $\mathrm{~m}$ \\
\hline $\mathrm{C}$ & Chord of Tail Fin & 0.015 & $\mathrm{~m}$ \\
\hline
\end{tabular}




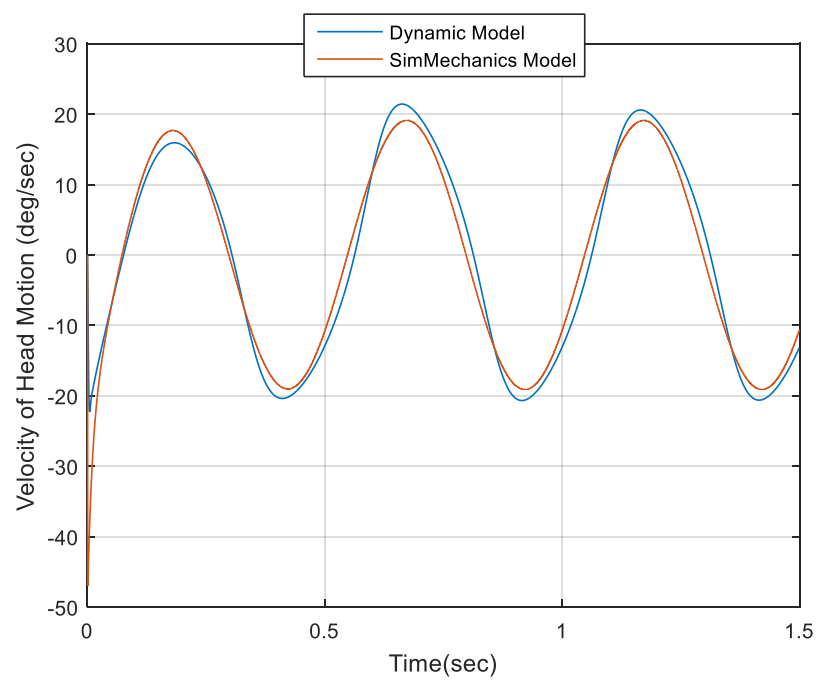

Figure 6. Angular velocity of the main body

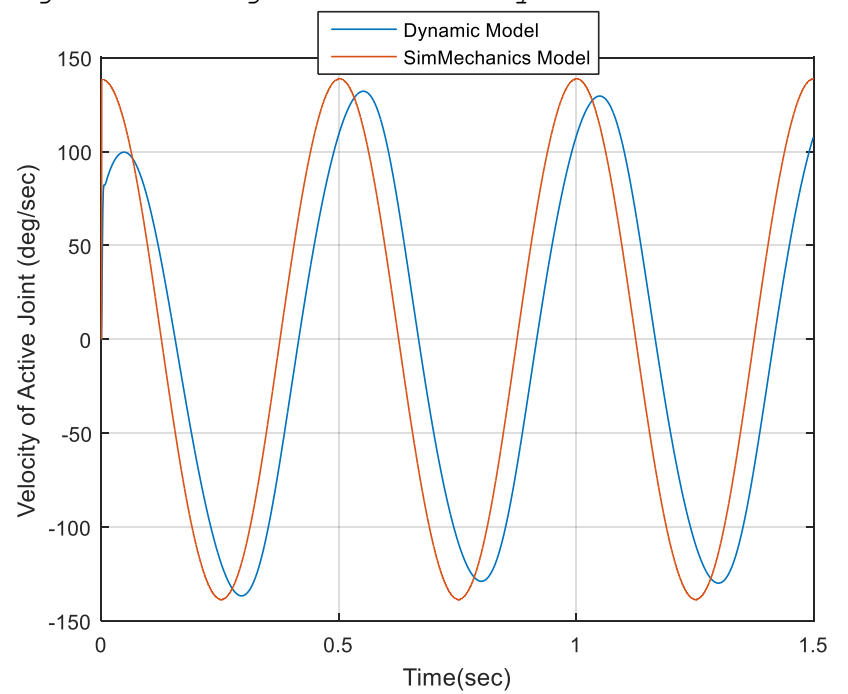

Figure 7. Angular velocity of the tail body

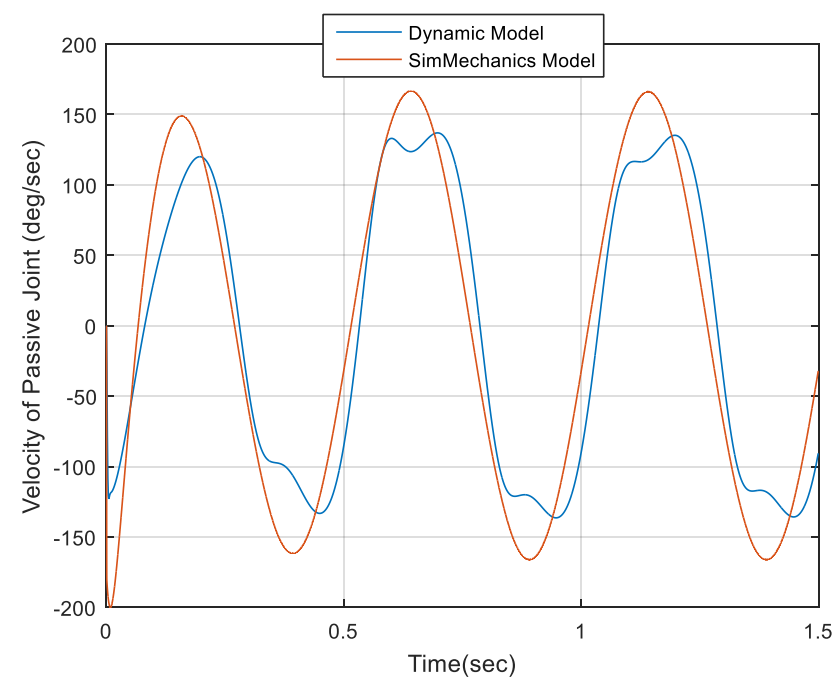

Figure 8. Angular velocity of the tail fin 
Akpolat, Z.H., Bingöl, M.C., Ay, M., Özmen Koca, G., Bal, C., and Korkmaz, D., Engineering Sciences (NWSAENS), 1A0370, 2017; 12(1): 29-39.

From Figure 9 to 11 present position of main body, tail body and tail fin of the robotic fish. Acceptable results are also obtained for angles of joints with the SimMechanics model.

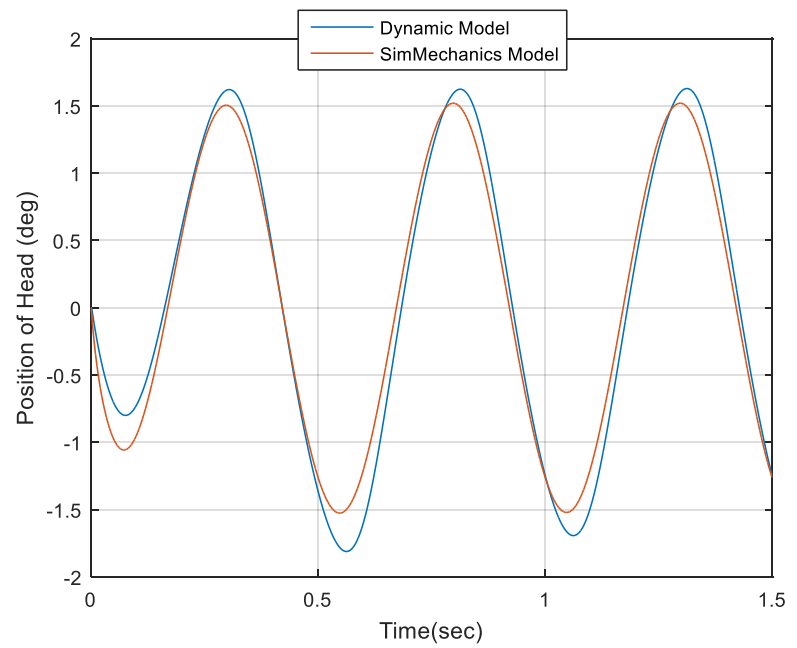

Figure 9. Angle of the main body

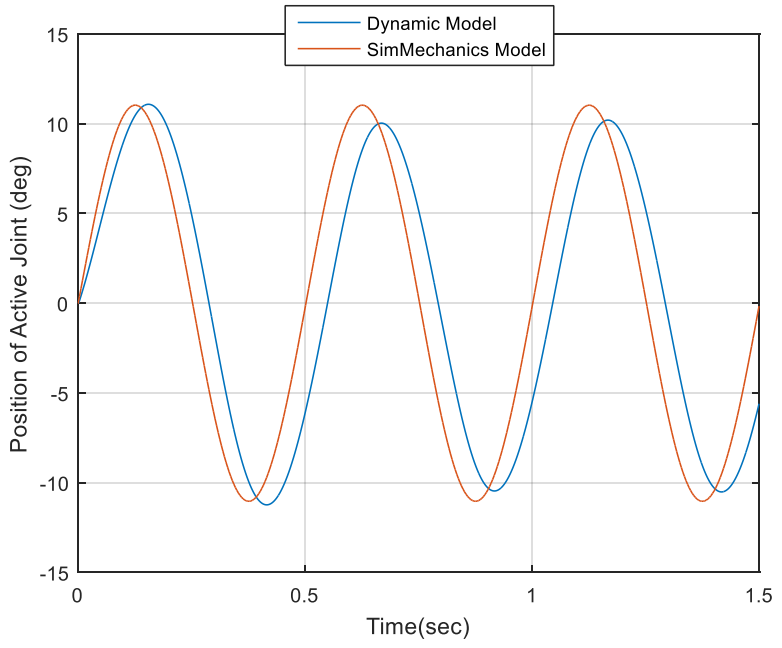

Figure 10. Angle of the tail body

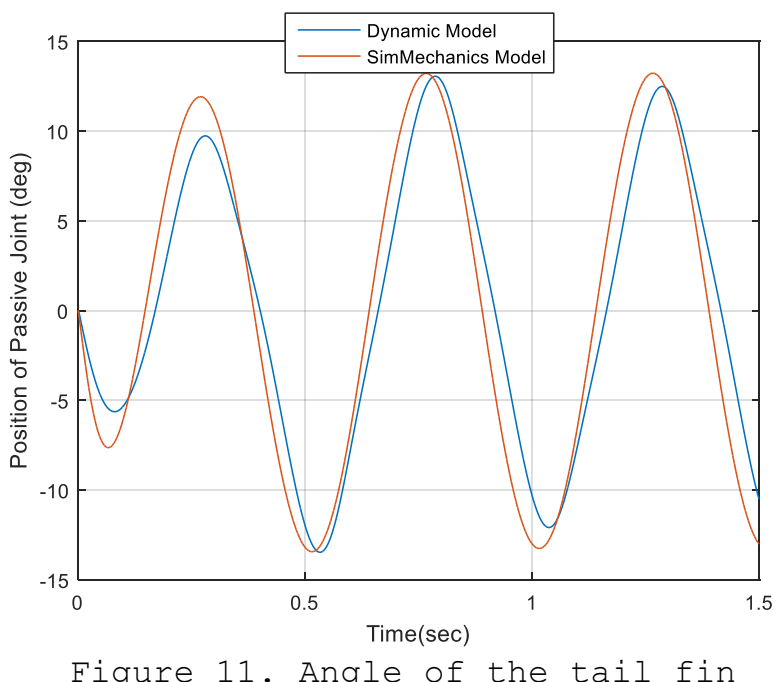


Animation of the robotic fish is presented in Figure 12 for different times with six images captured from the top view. In detailed animations can be found from https://youtu.be/IIqG_pAJdwA. Table 2 shows the joint angles stated in Figure 12 versus different time values.

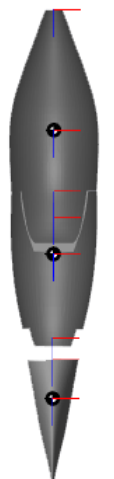

(a)

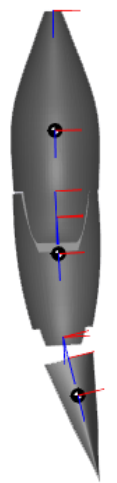

(d)

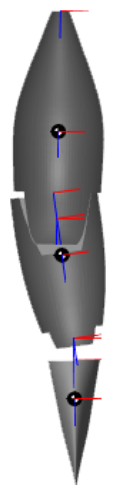

(b)

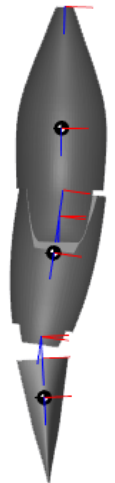

(e)

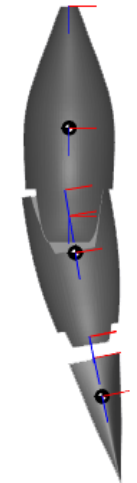

(c)

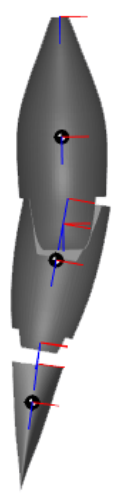

(f)

Figure 12. Animation of the robotic fish

Table 2. Animation parameters

\begin{tabular}{|c|c|c|c|c|}
\hline \multicolumn{6}{|c|}{ Values of the Animation and Picture Locations } \\
\hline Time (sec.) & $\theta_{1}($ deg.) & $\theta_{2}$ (deg.) & $\theta_{3}$ (deg.) & Picture \\
\hline 0.00 & $0.0000^{\circ}$ & $0.000^{\circ}$ & $0.000^{\circ}$ & $(\mathrm{a})$ \\
\hline 0.08 & $-1.0453^{\circ}$ & $9.3151^{\circ}$ & $-7.2886^{\circ}$ & (b) \\
\hline 0.16 & $-0.1370^{\circ}$ & $9.9987^{\circ}$ & $1^{\circ} .9570^{\circ}$ & (c) \\
\hline 0.23 & $1.0275^{\circ}$ & $2.7612^{\circ}$ & $10.491^{\circ}$ & (d) \\
\hline 0.30 & $-1.5020^{\circ}$ & $-6.4717^{\circ}$ & $10.839^{\circ}$ & (e) \\
\hline 0.37 & $0.8920^{\circ}$ & $-11.009^{\circ}$ & $2.5870^{\circ}$ & (f) \\
\hline
\end{tabular}

It can be seen from Figure 12 that obtained joint angles from SimMechanics model of the robotic fish can animate the robot as a real fish motion in forward swimming mode. 


\section{CONCLUSION}

In this study, two different models which are simple SimMechanics and complex dynamic model of the one active joint robotic fish are designed. The parts of the robotic fish are drawn by using solidWorks and then CAD model is assembled in this environment. This CAD model is implemented to SimMechanics environment to provide first generation without hydrodynamic effects. The complete SimMechanics model is obtained by adding hydrodynamic forces and motor effects. Dynamic model of the robotic fish is also derived from Lagrange equations. Similar results are provided with two models. Thus, the simple simMechanics model of the robotic fish can be used instead of complex dynamic model, if one designs a controller for the system. In future works, 3D motion of the robotic fish in $x, y$, and $z$ axis can be implemented. 3D trajectory tracking can also be provided with this $3 D$ model of the robotic fish.

\section{ACKNOWLEDGMENT}

This research is supported by the number of $114 \mathrm{E} 652$ TUBITAK 1001 project. We thank because of the financial support and guiding reports.

\section{NOTE}

After this study presented as oral presentation at International Science Symposium (ISS2016) in İstanbul-Büyükada between dates 01-04 September 2016, it expanded and restructure.

\section{REFERENCES}

1. Liu, T.J. and Hu H., (2010). Biological Inspiration: From Carangiform Fish to Multi-Joint Robotic Fish, Journal of Bionic Engineering, Volume: 7 .

2. Yan, Q., Han, Z., Zhang, S., and Yang, J., (2008). Parametric Research of Experiments on a Carangiform Robotic Fish, Journal of Bionic Engineering, Volume:5.

3. Vo, T.Q., Kim, H.S., and Lee, B.R., (2009). Propulsive Velocity Optimization of 3-Joint Fish Robot Using Genetic-Hill Climbing Algorithm, Journal of Bionic Engineering, Volume:6.

4. Ren, Q., Xu, J., and Li, X., (2015). A Data-driven Motion Control Approach for a Robotic Fish, Journal of Bionic Engineering, Volume:12.

5. Yu, J. and Yi, C., (2009). Analysis of Relationship between Efficiency and Motion Parameters of Robotic Fish, Intelligent Human-Machine Systems and Cybernetics.

6. Hirata K., (?). Design and Manufacturing of a Small Fish Robot, Processing of Japan Society for Design Engineering.

7. Triantafyllou, M.S. and Triantafyllou, G.S., (1995). An Efficient Swimming Machine, Scientific American, Vol:272.

8. Zhou, C., Tan, M., Cao, Z., Wang, S., Creighton, D., Gu, N., and Nahavandi, S., (2008). Kinematic Modeling of a Bio-inspired Robotic Fish, ICRA 2008.

9. Suebsaiprom, P. and Lin, C., (2015). Maneuverability Modeling And Trajectory Tracking For Fish Robot, Control Engineering Practice, Volume:45.

10. Wang, J., Alequin-Ramos, F., and Tan, X., (2011). Dynamic Modeling of Robotic Fish and its Experimental Validation, Intelligent Robots and Systems (IROS).

11. Ding, R., Yu, J., Yang, Q., Tan, M., and Zhang, J., (2009). CPGBased Dynamics Modeling and Simulation for a Biomimetic Amphibious Robot, in Robotics and Biomimetics (ROBIO), 2009 IEEE International Conference on, pp:1657-1662. 
Akpolat, Z.H., Bingöl, M.C., Ay, M., Özmen Koca, G., Bal, C., and Korkmaz, D., Engineering Sciences (NWSAENS), 1A0370, 2017; 12(1): 29-39.

12. Chowdhury, A.R., Prasad, B., Kumar, V., Kumar, R., and Panda, S.K., (2011). Design Modeling and Open-Loop Control of a BCF Mode Bio-Mimetic Robotic Fish, 2011 IEEE International Symposium on Safety, Security, and Rescue Robotics, Kyoto, pp:226-231.

13. Zhou, C., Cao, Z., Wang, S., and Tan, M., (2008). The Dynamic Analysis of the Backward Swimming Mode for Biomimetic Carangiform Robotic Fish, 2008 IEEE/RSJ International Conference on Intelligent Robots and Systems, Nice, pp:3072-3076.

14. Dung, L.T., Kang, H., and Ro, Y., (2010). Robot Manipulator Modeling in Matlab-Simmechanics with PD Control and Online Gravity Compensation, in Strategic Technology (IFOST), 2010 International Forum on, pp:446-449.

15. Liui J., Cheni G., Gongi Y., and Cheni H., (2011). Modeling and Simulation of Loader Working Device Based on Simmechanics, in Transportation, Mechanical, and Electrical Engineering (TMEE), 2011 International Conference on, pp:2054-2057.

16. Fatehi, M.H., Vali, A.R., Eghtesad, M., and Fatehi, A.A., (2011). Modeling and Control of 3-PRS Parallel Robot and Simulation Based on SimMechanics in MATLAB, Instrumentation and Automation (ICCIA), 2011 2nd International Conference on, pp: $785-790$.

17. Tang, L., Zhang, L., and Ru, F., (2012). SimMechanics Model and LQR Control for Linear Double Inversed Pendulum Based on Kalman Filter, in Systems and Informatics (ICSAI), 2012 International Conference on, pp:462-464.

18. Ding, B., Li, Y., and Tang, Y., (2015). Workspace analysis for a 3-DOF Compliant Parallel Mechanism Based on SimMechanics, in Cybernetics and Intelligent systems (CIS) and IEEE Conference on Robotics, Automation and Mechatronics (RAM), 2015 IEEE 7th International Conference on, pp:48-53. 